UDC 53.087.4:533.9.07

PACS $52.59 \mathrm{Ye}, 07.05 \mathrm{Dz}$

DOI: $10.22363 / 2658-4670-2021-29-3-205-220$

\title{
Modeling and design of an re-configurable isolated remote for plasma experiments with hard-real-time synchronization
}

\author{
Viktor V. Andreev, Denis V. Chuprov \\ Peoples' Friendship University of Russia (RUDN University) \\ 6, Miklukho-Maklaya St., Moscow, 117198, Russian Federation
}

(received: July 24, 2021; accepted: September 9, 2021)

The purpose of this paper is to present the design and implementation of a reconfigurable remote control for performing plasma experiments with Hard-Real-Time (HRT) synchronization under jitter less than 1 microsecond. An additional requirement for a multichannel synchronization system is the use of high-speed optical converters to provide galvanic isolation between powerful modules of the setup and remote control in order to exclude any possibility of disruption of the physical experiment control system.

Modeling and development of the software part of the maser remote control panel was performed in the LabVIEW application development environment with Real Time and FPGA modules.

The hardware part of the control panel is implemented on a real-time controller working in conjunction with the Xilinx FPGA module. To ensure the optical isolation of synchronization signals, boards of electron-optical converters based on LED lasers with fiber-optic terminals were developed and manufactured.

The control program is implemented in a two-module architecture with a HOST application and an FPGA application that exchange data over a 1000BASE-T Ethernet network.

Key words and phrases: remote control, synchronization, hard real-time system, FPGA, reconfigurable input-output (RIO)

\section{Introduction}

Control of a complex multi-parameter physics experiment places high demands on the synchronization of the operation of various systems, nodes and modules of the experimental setup [1]-[3]. In such case, controllability is defined as the ability of the remote control system to achieve a define state when several processes work together or in a certain experiment scenario in a time sequence [4]. Real-time systems must accomplish executive and application tasks within specified timing constraints [5], [6]. The time resolution -

(C) Andreev V.V., Chuprov D. V., 2021

This work is licensed under a Creative Commons Attribution 4.0 International License 
the minimum distinguishable step along the time axis-is in this case the most important characteristic of the synchronization system. So simultaneity of processes or phenomena is reduced to the fact that these processes on the time axis are separated from each other by intervals that do not exceed the time resolution of the system.

The use in physics experiment high-voltage AC and DC or UHF power systems generates a high level of electromagnetic noise and in this case the concept of Power-over-Fiber technology is applied to ensure controllability [7], [8]. Thus, the safety regulations for equipment operating at high power levels, along with the serious requirements for the reliability of the electronics in harsh environments, require galvanic isolation [9], [10].

Our work on synchronization in HRT systems has been performed as part of an ongoing autoresonance plasma experiments in Plasma physics laboratory of RUDN [11], [12]. To organize the operation of the synchronization system, a single time reference point is selected, and the characteristic stages of each of the processes are separated from this beginning by an adjustable amount of delay. The device that provides a countdown of the required delay was called a delay generator. The developed concept can easily be scaled practically on any type of complicated plasma experiments.

\section{Experimental setup}

As an example of a complex physical installation that requires control with real time synchronization, consider the problem of controlling a plasma maser. A plasma maser (plasma relativistic microwave generator) is a source of powerful microwave radiation in which the Cherenkov effect of the interaction of a high-current relativistic electron beam (REB) with a slow wave of a plasma waveguide is realized [13]-[15]. The configurations of plasma masers differ in the relative position of the REB and plasma and are described in detail in [16], [17].

In the maser scheme implemented in this project, the REB propagates in a strong longitudinal magnetic field in a metal cylindrical waveguide, in which a plasma with controlled parameters is pre-created.

A simplified block diagram of the created plasma maser is shown in the figure 1 and includes an main experimental setup and a system for ensuring its operation.

The main experimental setup includes 4 modules:

- A generator of periodic high-voltage pulses of nanosecond duration as a source of a high-current REB in a direct-acting accelerator based on an explosive-emission cathode.

- A plasma source with controlled parameters.

- The space of formation of REB and plasma in a strong magnetic field.

- Remote control of all nodes and diagnostic systems.

The support system consists of:

- A vacuum pumping system.

- Gas inlet system for creating plasma.

- A system for converting a plasma wave into an electromagnetic wave, releasing radiation into the atmosphere, focusing it, and transporting it.

- Radiation detection and diagnostics system. 


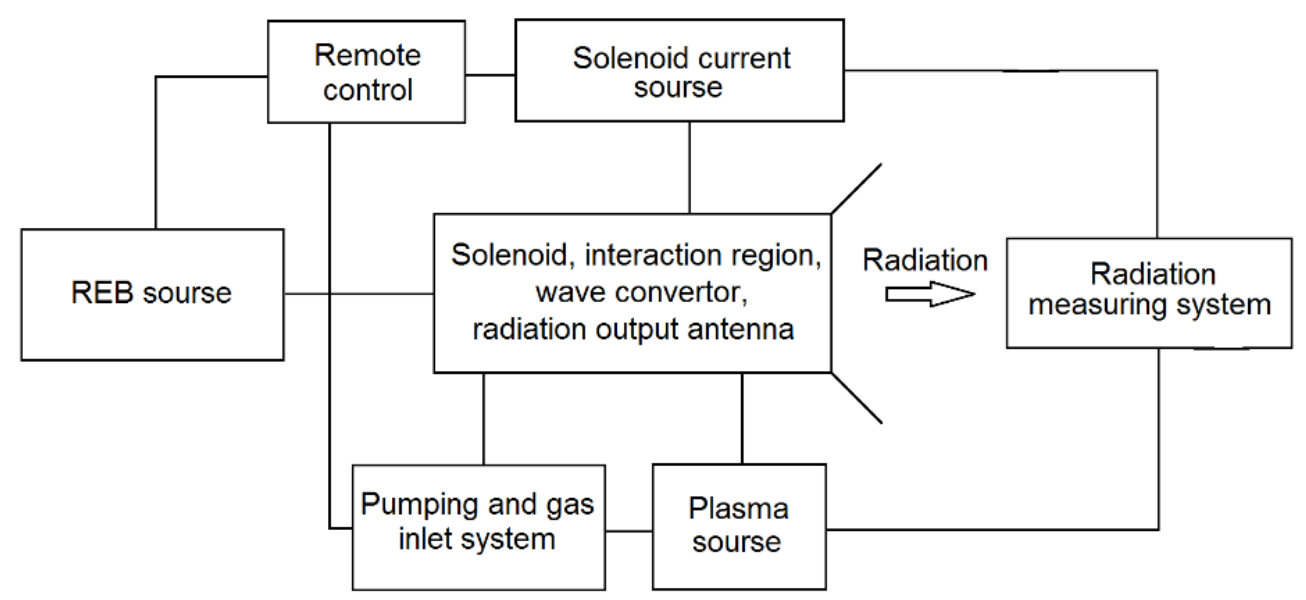

Figure 1. Block diagram of a plasma maser

The operation of all the main operating systems of the plasma maser is provided by a synchronization system with a strict reference to real time. This system is integrated into the control panel, where the operator sets the required operation scenario, provides a physical start of the maser and receives a report in the form of tabular and graphical data on the state of the maser subsystems at synchronous times of the working cycle. Schematically, the maser operation scenario is shown in the figure 2 .

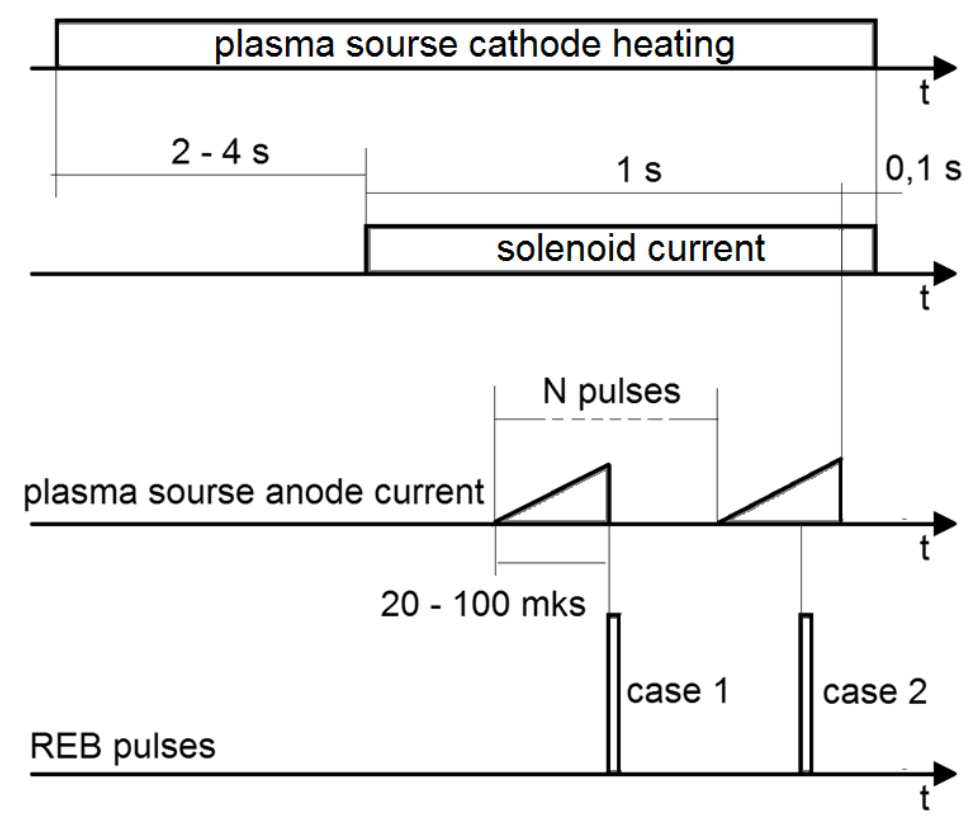

Figure 2. Plasma maser working scenario

If the warm solenoid is ready, after 30 seconds after all the limit switches (locks) are triggered, a ready signal is generated - the "Start" button in the 
remote control interface is activated. Pressing the "Start" button generates a "glow" pulse, which is applied to the power supply of the plasma source.

After the set time "Glow duration" (set by the operator in the range of $0-5 \mathrm{~s}$ ), the signal "solenoid current" is generated. After the battery charge current of the solenoid reaches the set values, the remote control generates a burst of pulses with the set frequency during $1 \mathrm{~s}$.

The developed remote control allows the operator to implement two options for starting the maser. In case 1 (see the figure 2) a beam of relativistic electrons interacts with a "quiet" plasma in the absence of current in the cathode circuit of the plasma generator. The plasma decay time is of the order of tens to hundreds of microseconds, so synchronization with a jitter of the order of 1 microsecond is enough. In the development of the launch scenario according to the case 2 option, the REB interacts with the plasma under conditions of increasing concentration. One of the tasks of the experiment is to compare the two described scenarios and identify the preferred conditions for the occurrence and development of a plasma-beam discharge in terms of obtaining a powerful broadband EMR pulse.

After a time of about $1 \mathrm{~ms}$ after the last pulse of the bundle, the remote control generates the endings (trailing edges) of the current pulses of both warm solenoids and the glow pulse of the thermocathode.

The developed remote provides control of the signals of the security system, as well as the generation of appropriate enabling, warning, or prohibiting signals and commands.

The NI cRIO-9053 chassis (see the figure 3(a)) with a real-time controller and an integrated field-programmable gate array (FPGA) chip was chosen as the hardware platform of the synchronization system. The FPGA architecture is a set of programatically configurable logic blocks, the connections between them, and the I/O blocks. This structure is best suited to the tasks of parallel multi-channel data processing to multi-channel signal generation.

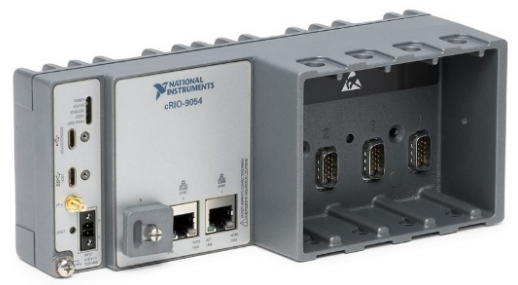

(a)
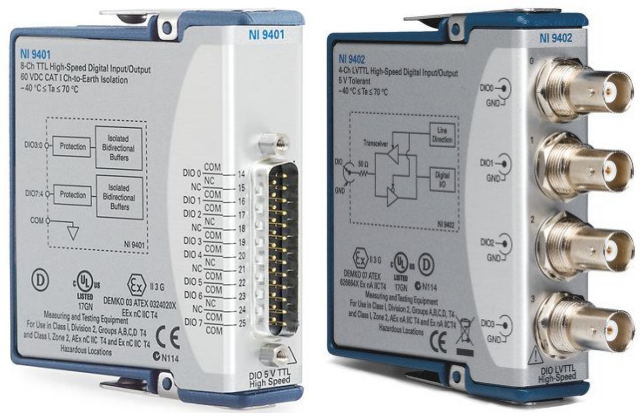

(b)

Figure 3. NI cRIO-9053 chassis (a); I/O modules NI 9401 and NI 9402 (b)

The reconfigurable I/O modules NI 9401 and NI 9402 were used for matching with the generator loads - input channels of synchronized devices (see the figure 3(b)). They have a similar circuit architecture but differ in the maximum switching speed and the form factor of the output connectors. This solution is chosen to conditionally divide the input and output signals into 
two groups: "fast" signals with strict jitter requirements (starting the plasma generation and starting the REB source) and "slow" signals with a relatively less rigid reference to real time (starting the heating of the thermal cathode, starting the solenoid current generator and emergency lock signals).

Main characteristics of the controller and modules:

- 4-slot CompactRIO controller, 1.30 GHz Dual-core CPU, 4 GB DRAM, 4 GB Storage, $-20^{\circ} \mathrm{C}$ to $55^{\circ} \mathrm{C}$, Artix-7 50T FPGA. The cRIO- 9053 controller is a secure, high-performance, customizable embedded controller that contains a dual-core Intel Atom processor, an Artix-7 FPGA, and four slots for C-series modules. It runs on the NI Linux Real-Time operating system with $\mathrm{I} / \mathrm{O}$ access via the NI-DAQmx drivers or via the LabVIEW FPGA module.

- The NI 9401 module provides a reconfigurable I/O interface for digital lines in 4-bit increments and operates in three configurations: 8 digital inputs, 8 digital outputs, or 4 digital inputs and outputs each. The pulse font is not worse than $100 \mathrm{~ns}$. The signal level is $5 \mathrm{~V}$ TTL. Output connector 25 PIN D-SUB.

- The NI 9402 module provides a reconfigurable I/O interface for 4 digital lines, operating in two configurations: 4 digital inputs, or 4 digital outputs. The pulse font is not worse than $50 \mathrm{~ns}$. The signal strength is 3.3 V LVTTL. 4X BNC (50 Ohm) output connector.

A digital 4-channel RIGOL MSO1074 oscilloscope with a bandwidth of $70 \mathrm{MHz}$ and a minimum detectable pulse duration of $10 \mathrm{~ns}$ was used to monitor the system and perform test measurements.

\section{Results and conclusion}

A program of control of the prototype generator was created in the LabVIEW graphical programming environment [18]-[20]. LabVIEW is one of the most popular development environments for modeling, simulation and equipment control applications.

The developed program consists of two parts: the top-level host program in the figure 4 is responsible for the user interface and transmits the synchronization system settings and setpoints to the FPGA program once per second. The current values of the settings are transmitted over the communication channel between the HOST and the FPGA applications.

In the FPGA program in the figure 5 after checking the health of all connected devices and assigning program identifiers to the physical synchronization channels, an infinite loop begins, working out the commands of the HOST application. After receiving the "START" command, the synchronization signals are switched on and off sequentially with the specified durations and delays for each of the active channels. After the plasma maser cycle is completed, the FPGA application signals this to the HOST application and goes back to standby mode.

The waveforms with the results of testing the program of the remote control are shown in the figure 6 . Beam 1 - the starting pulse, beam 2 the output pulse of one of the synchronization channels (starting the plasma generation). Tests have shown that the programmable delay of the generated signal corresponds to the setpoint with high accuracy. 


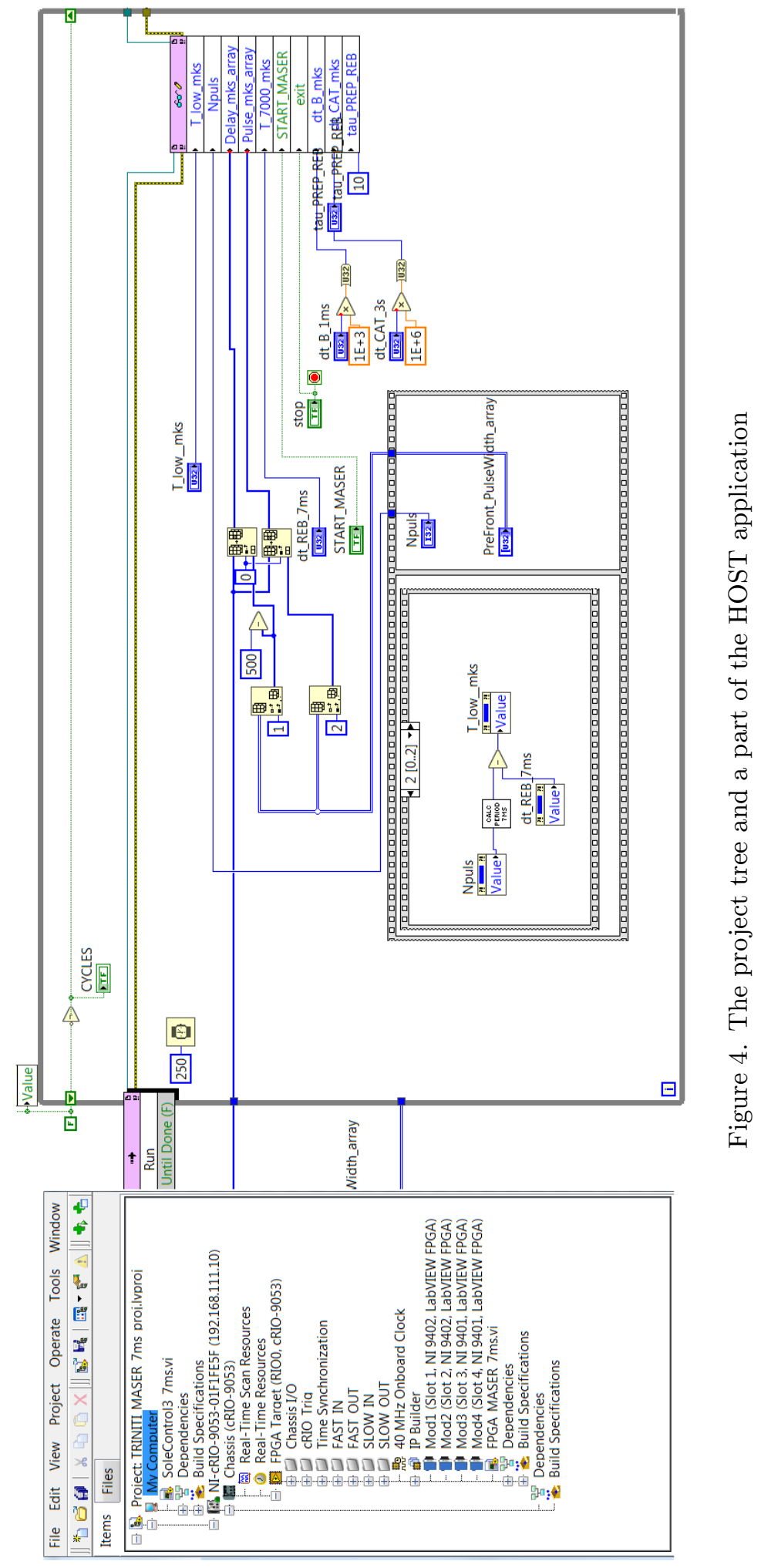




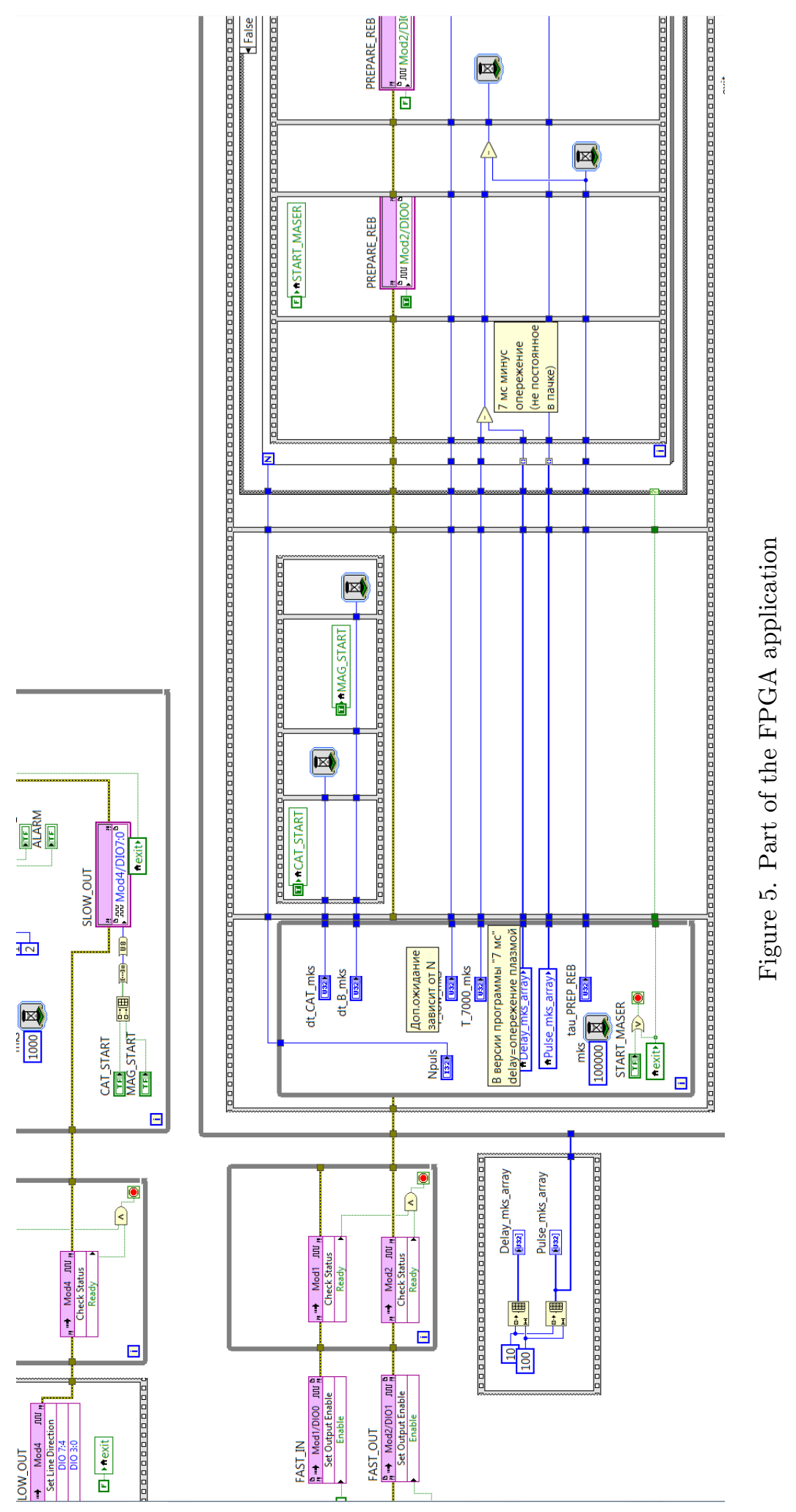


The jitter observed at the signal edges is less than $100 \mathrm{~ns}$ (it is not noticeable on the waveforms). The step of changing the programmable delay in the synchronization system channel is 1 microsecond. The delay can vary from 1 microsecond to $2^{32}$ microseconds (more than 1 hour).

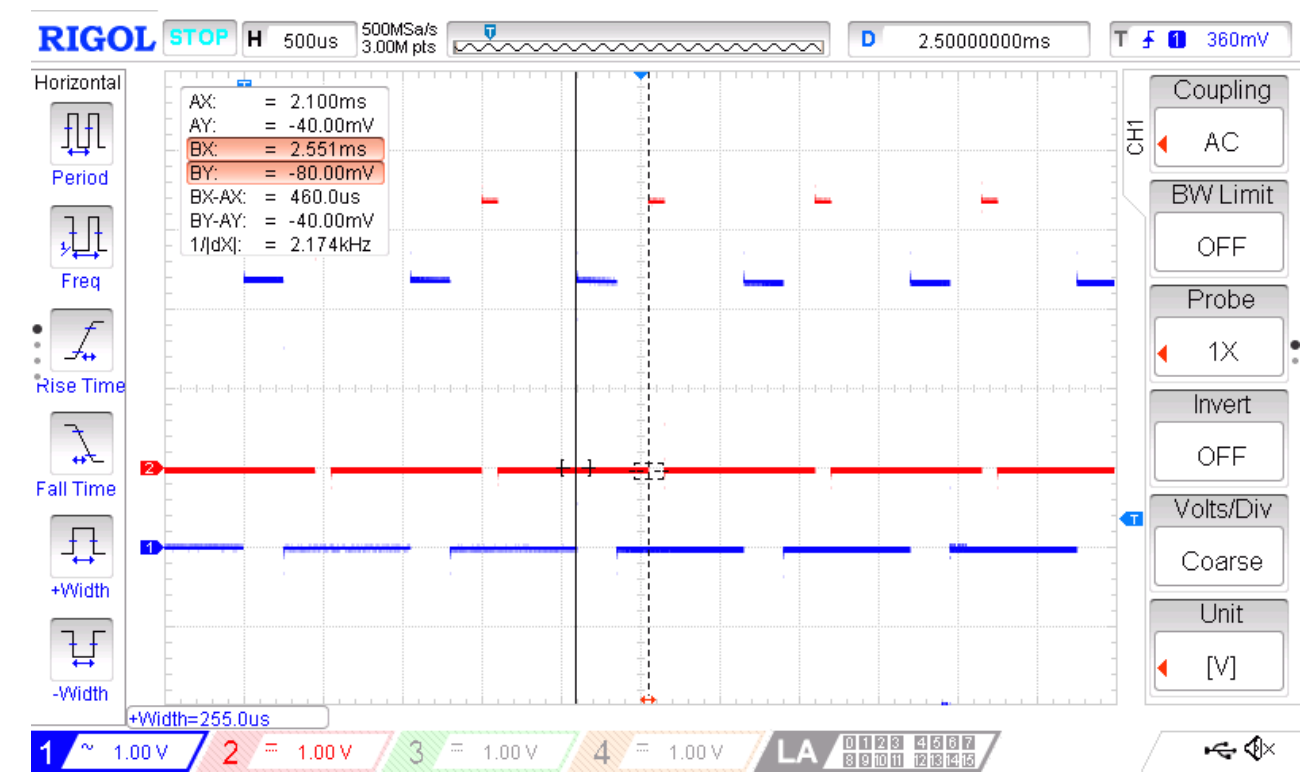

(a) Scan $500 \mathrm{~ms} /$ division

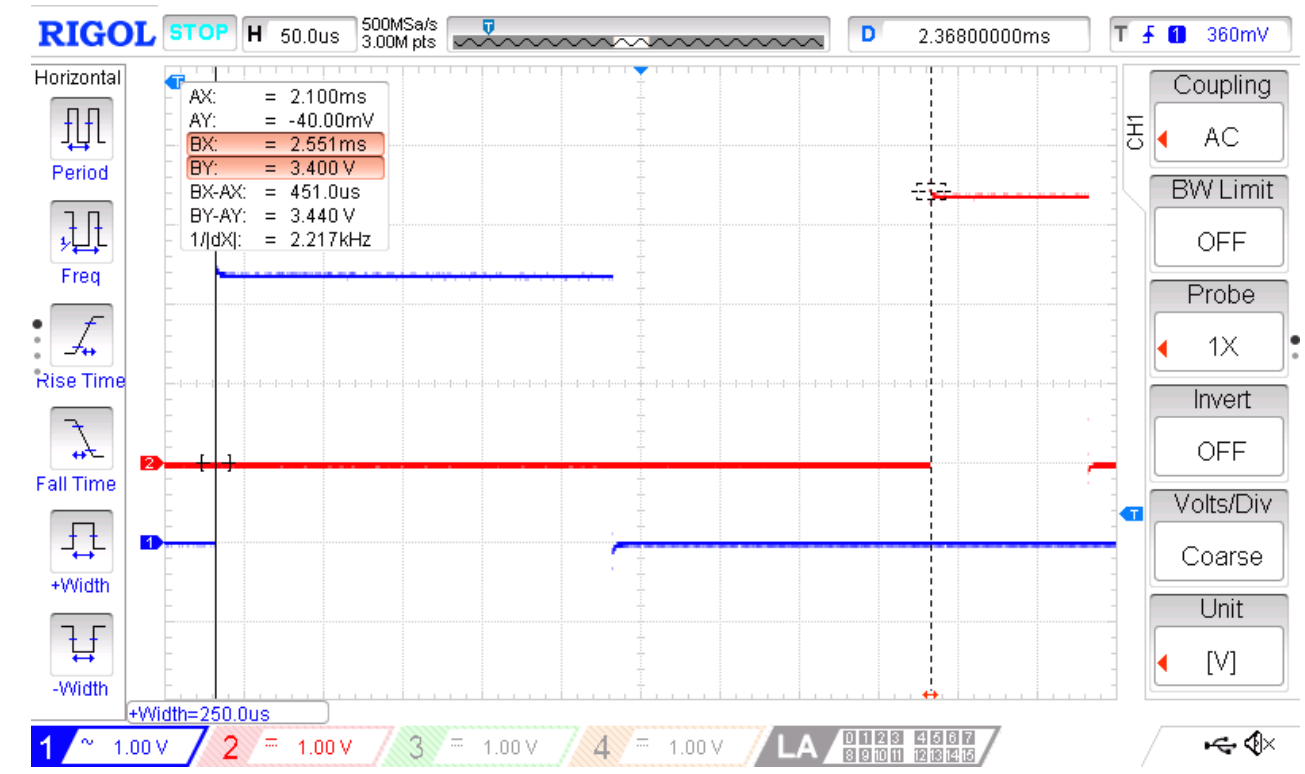

(b) Scan $50 \mathrm{~ms} /$ division

Figure 6. Waveforms of the operation of the plasma generation start channel in single-channel mode with a delay time setting of 450 microseconds 
The next stage of our tests was to check the software control of the delays in the generation of the REB relative to the front of the plasma pulse under the conditions of the generation of a pulse train. To configure program delays, the control program interface provides a function block, shown in the figure 7 .

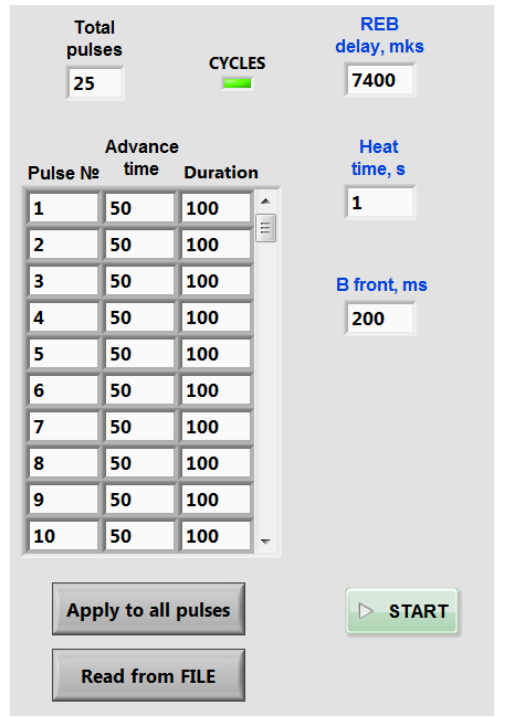

Figure 7. The control program interface block, with channel delay settings

After specifying the number of pulses in the packet, the values of the plasma pulse durations and lead times (by how many microseconds the front of the plasma pulse is ahead of the RAP pulse) should be entered in the program delay table for each pulse of the packet. The settings made in the first row can be applied to the entire table. It is possible to read the corresponding table from a text file in a similar format to the table. The separator is a Tab character, the line separators are the End Of Line character.

A series of waveforms showing the possibilities of software tuning of the advance is shown in figures $8,9,10$. The beam 2 is a synchropulse for plasma generation, the beam 1 is a program repeater of the REB pulse with a duration of 10 microseconds (for easy display on oscillograms).

It can be seen that the leading edge of the plasma pulse of the REB pulse strictly follows the setpoints of the control program interface (see the figure 7).

The created software and hardware complex allows you to scale the number of synchronization channels and, with the available equipment, get a total of 8 delay channels with edges no worse than 50 ns and 16 channels with edges no worse than 100 ns. The control panel based on the implemented synchronization system has shown the ability for long-term stable uninterrupted operation and is currently successfully used in experiments to select the optimal operating modes of a plasma maser. Additionally, if it is necessary to switch to a submicrosecond delay control step, the system can be reconfigured to work with synchronization directly from the FPGA clock generator. The existing FPGA platform with a clock frequency of $40 \mathrm{MHz}$ allows you to reduce the minimum step of regulating pulse durations and delays to $25 \mathrm{~ns}$. It should, however, be taken into account that the control range in this case will decrease by a multiple to a value of about 15 minutes. 


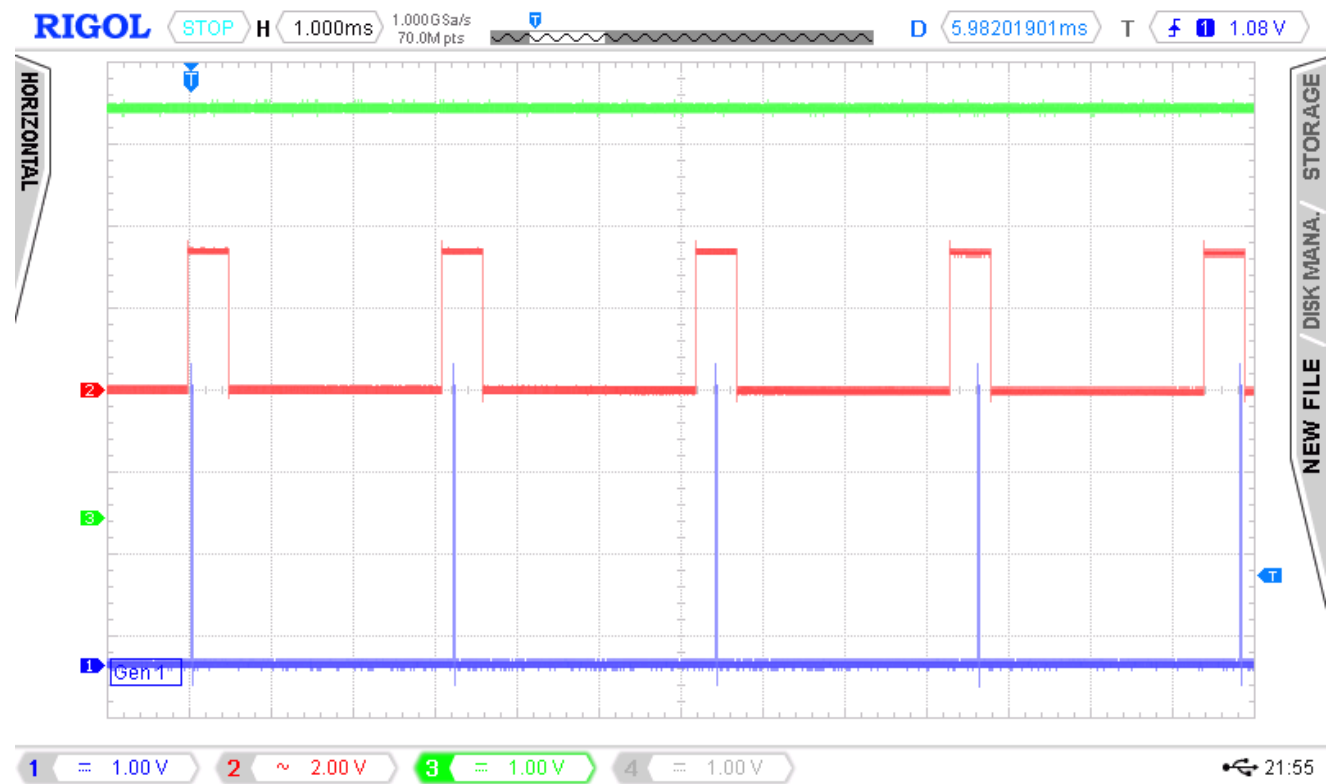

(a) the first five pulses of the pulse train with a controlled advance of the REB pulse (beam 1) by the pulse front of the plasma generator (beam 2)

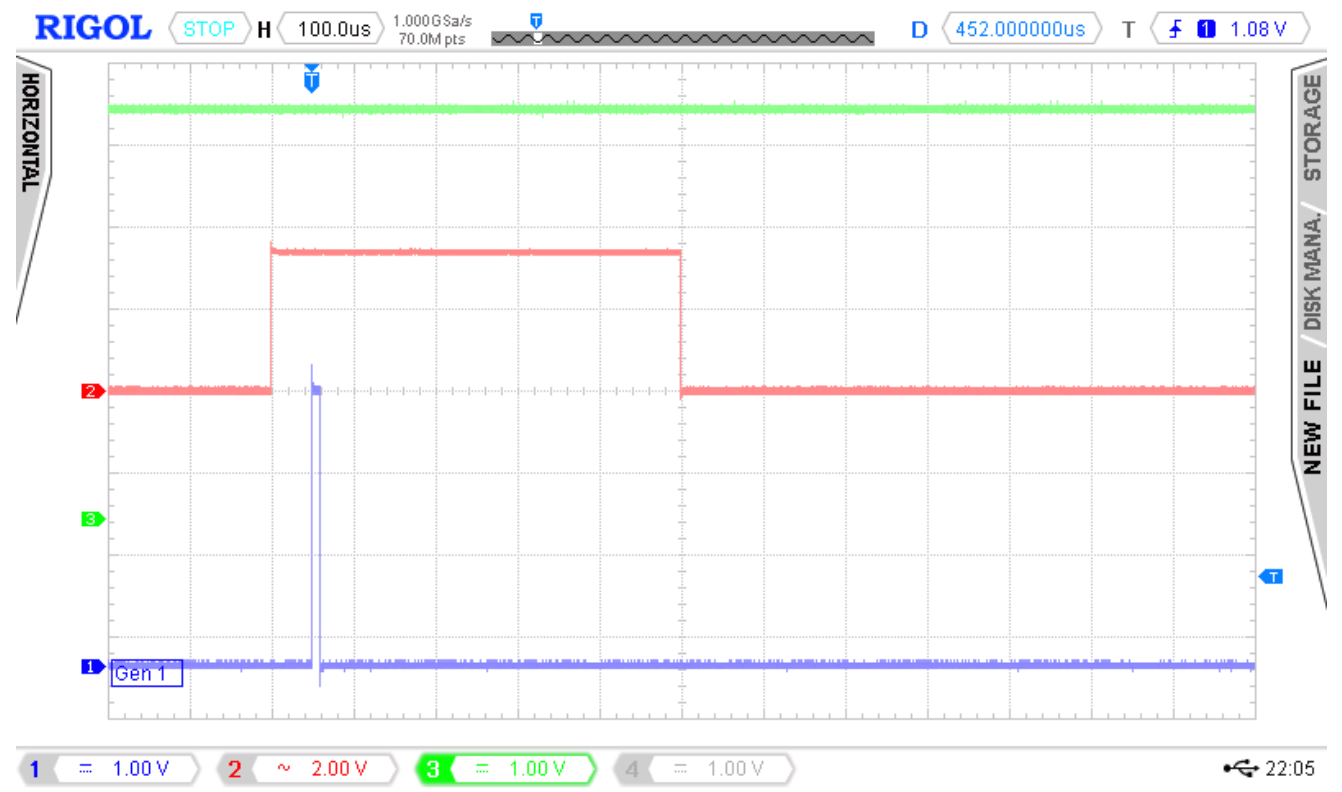

(b) the 1-st pulse of the pulse train with advances of 50 microseconds

Figure 8. The possibilities of tuning the advance between channels in the pulse train generation mode 


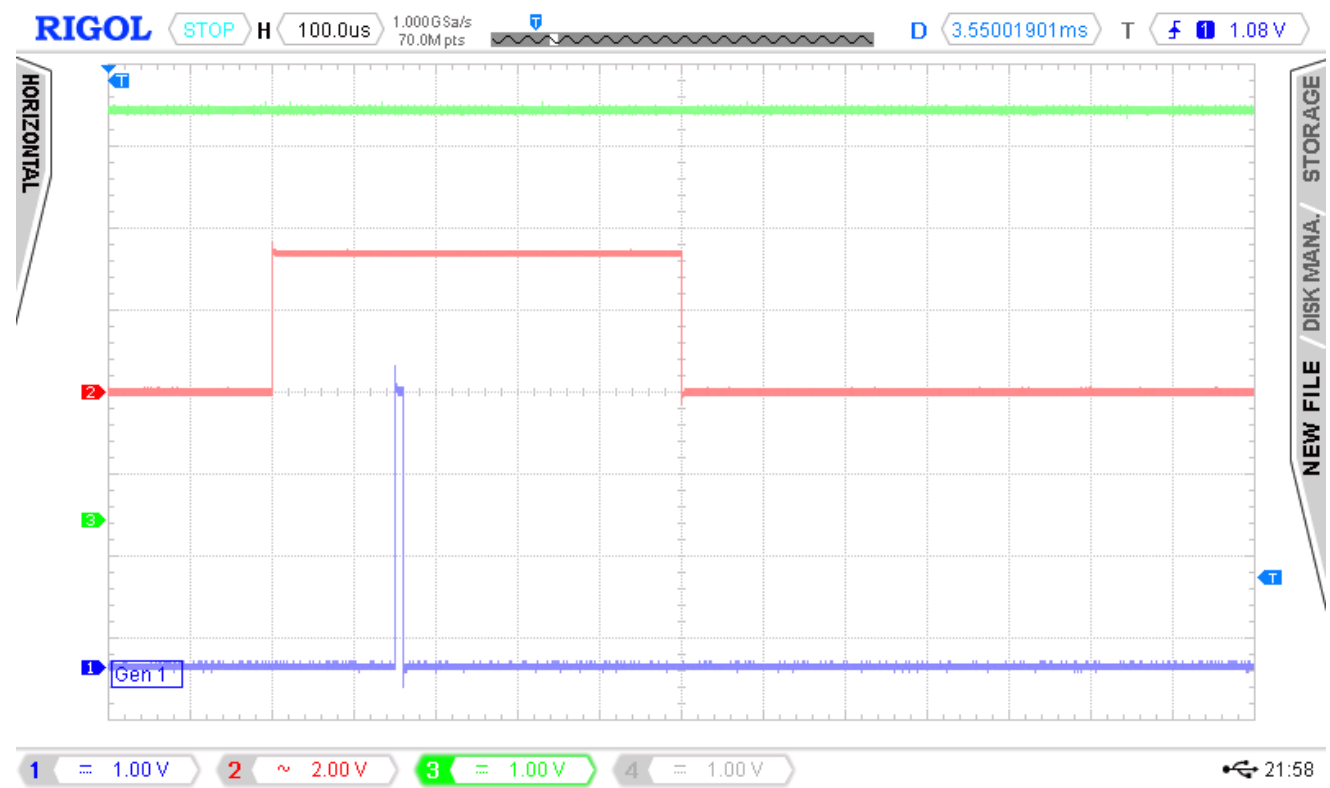

(a) the 2-nd pulse of the pulse train with advances of 150 microseconds

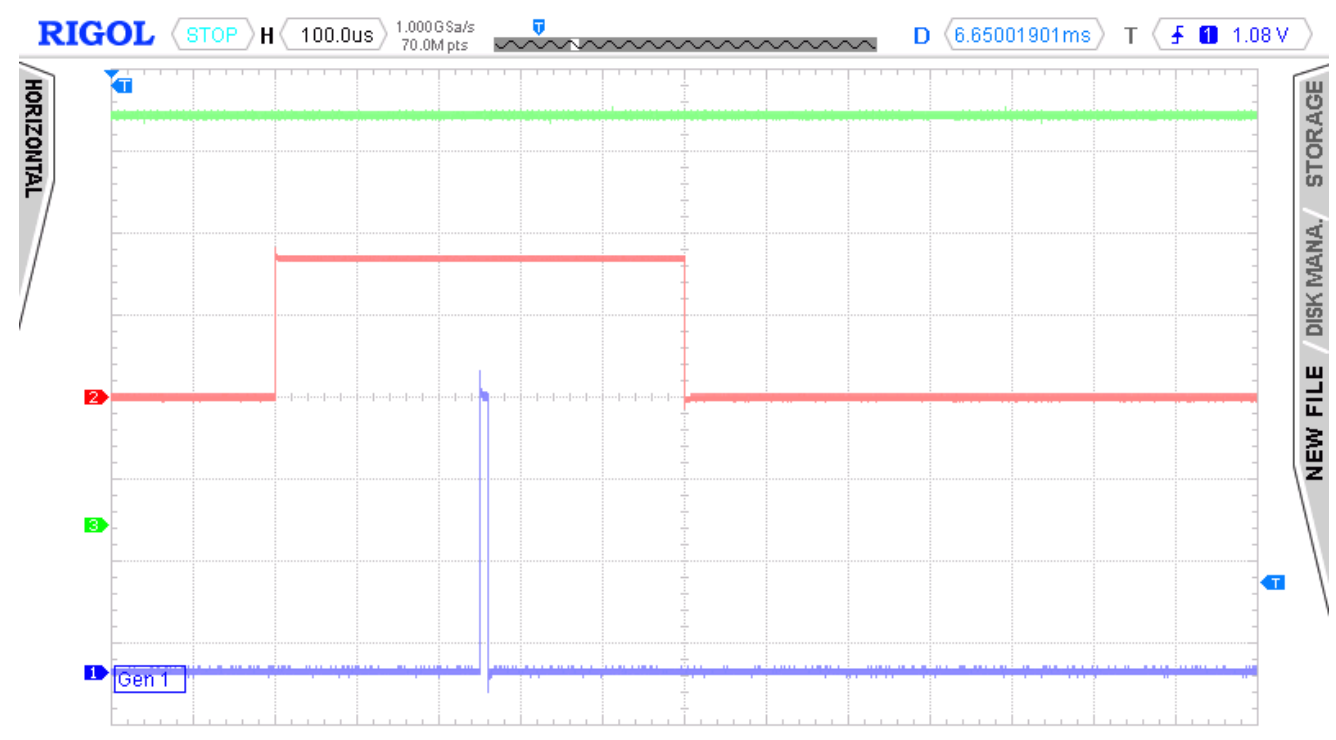

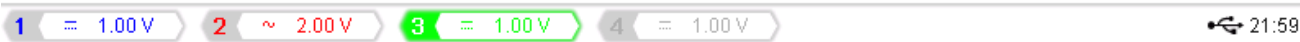

(b) the 3-rd pulse of the pulse train with advances of 250 microseconds

Figure 9. The possibilities of tuning the advance between channels in the pulse train generation mode 


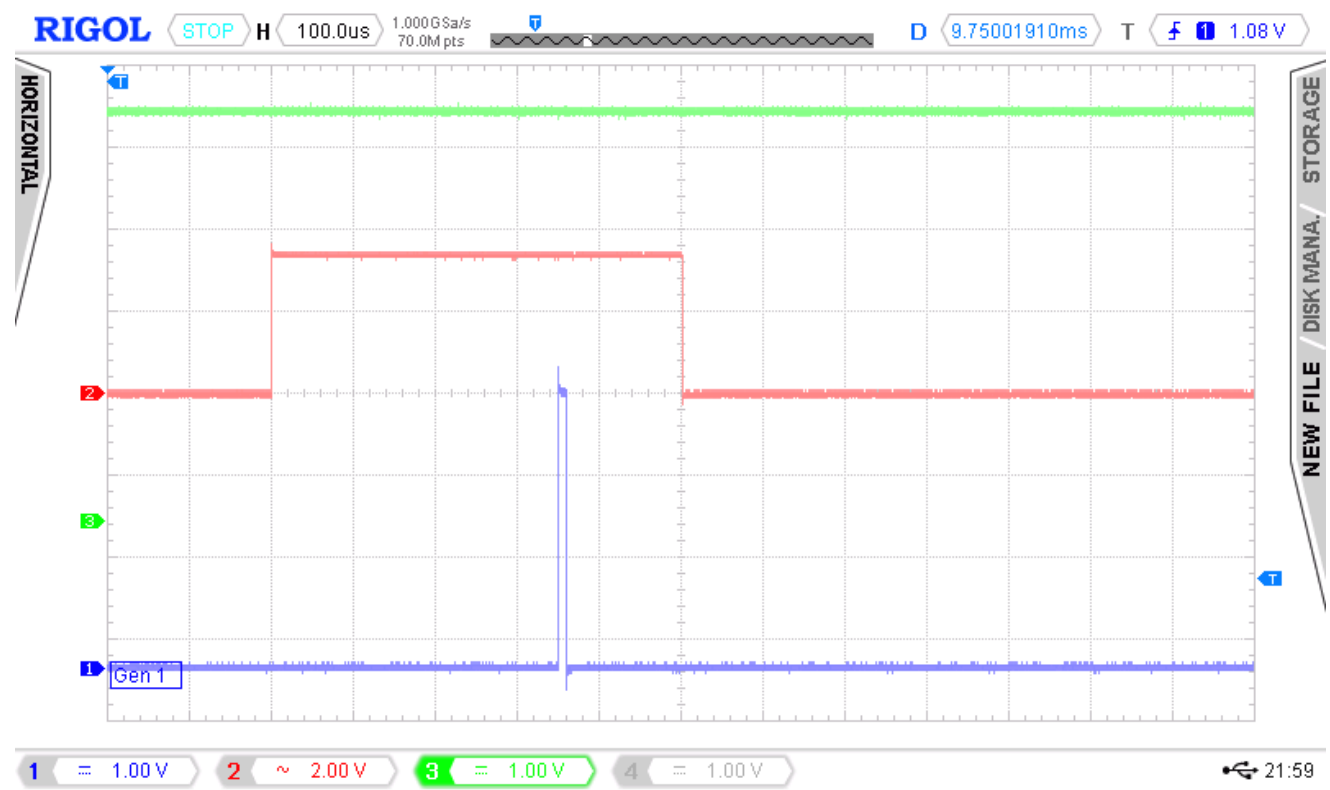

(a) the 4-th pulse of the pulse train with advances of 350 microseconds

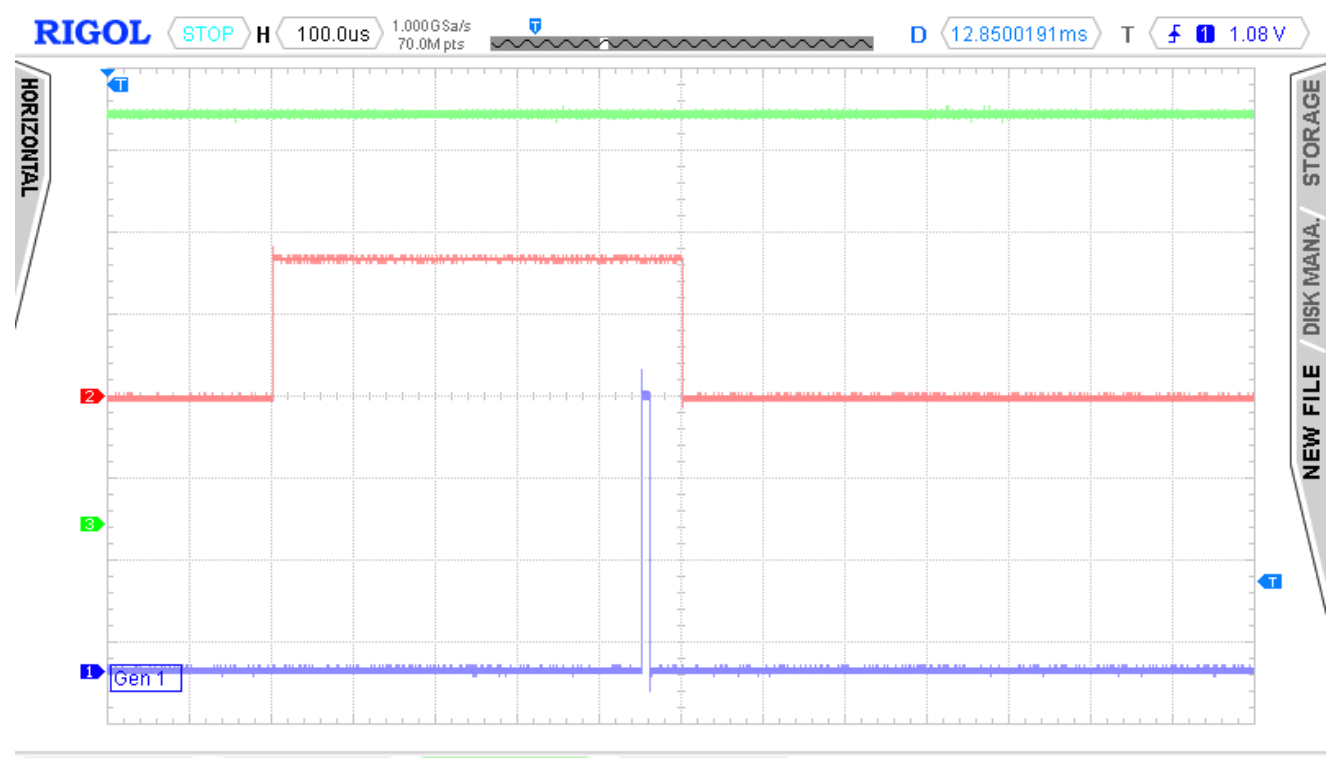

$1-1.00 \mathrm{~V} 2 \sim 2.00 \mathrm{~V} 3 \mathrm{3}-1.00 \mathrm{~V} 4 \mathrm{~V}=1.00 \mathrm{~V}$ • $22: 00$

(b) the 5-th pulse of the pulse train with advances of 450 microseconds

Figure 10. The possibilities of tuning the advance between channels in the pulse train generation mode 
The developed multi-channel synchronization system with fiber-optic galvanic isolation of the controller and secondary circuits of the equipment can be easily adapted to any tasks of controlling a physical experiment. This, in particular, is in demand when conducting experiments with cold plasma in the IFIT RUDN. These experiments require synchronization of the operation of a high-power microwave generator and a pulse current generator, as well as synchronized measurements of radiation parameters from the region of the plasma clot localization in the microwave, optical and X-ray ranges, probe measurements in the low-frequency and microwave ranges, etc. With the help of the created system, it is possible to provide such synchronization with a time resolution of at least 1 microsecond.

\section{Acknowledgement}

The reported study was funded by RFBR, project number 18-29-21041 (recipient D.V. Chuprov, Results and conclusion) and partially agreement 226/2480 (recipient V.V. Andreev, experimental setup).

\section{References}

[1] K. Patel, N. Umesh, H. C. Joshi, S. Pathak, K. A. Jadeja, K. Patel, and R. L. Tanna, "LabVIEW-FPGA-based real-time data acquisition system for ADITYA-U heterodyne interferometry," IEEE Transactions on Plasma Science, vol. 49, no. 6, pp. 1891-1897, 2021. DOI: 10.1109/ TPS. 2021.3082159.

[2] M. Kim and M. Kwon, "LabVIEW-EPICS interfaces in KSTAR control system," in Proc. 9th Int. Conf. on Accelerator and Large Experimental Physics Control Systems (ICALEPCS'03), Paper MP519, Gyeongju, Korea, Oct. 2003, pp. 87-89.

[3] Y. Ege, M. Kabadayi, O. Kalender, M. Coramik, H. Citak, E. Yuruklu, and A. Dalcali, "A new electromagnetic helical coilgun launcher design based on LabVIEW," IEEE Transactions on Plasma Science, vol. 44, no. 7, pp. 1208-1218, 2016. DOI: 10.1109/TPS.2016.2575080.

[4] P. S. Korenev, Y. V. Mitrishkin, and M. I. Patrov, "Reconstruction of equilibrium distribution of Tokamak plasma parameters by external magnetic measurements and construction of linear plasma models [Rekonstruktsiya ravnovesnogo raspredeleniya parametrov plazmy Tokamaka po vneshnim magnitnym izmereniyam i postroyeniye lineynykh plazmennykh modeley]," Mekhatronika, Avtomatizatsiya, Upravlenie, vol. 17, 4 2016, in Russian. DOI: 10.17587/mau.17.254-266.

[5] L. Giannone et al., "Real time magnetic field and flux measurements for tokamak control using a multi-core PCI Express system," in Proc. 25th SOFT, Id. Nr. 367, Rostock, Sep. 2008.

[6] J. H. Lee, S. H. Lee, S. H. Son, W. H. Ko, D. C. Seo, I. Yamada, K. H. Her, J. S. Jeon, and M. G. Bog, "Development of prototype polychromator system for KSTAR Thomson scattering diagnostic," Journal of Instrumentation, vol. 10, no. 12, p. C12012, Dec. 2015. DOI: 10.1088/1748-0221/10/12/c12012. 
[7] K. Sharifabadi, L. Harnefors, H.-P. Nee, S. Norrga, and R. Teodorescu, Design, control and application of modular multilevel converters for HVDC transmission systems. John Wiley \& Sons, Ltd., 2016.

[8] G. Anda, D. Dunai, M. Lampert, T. Krizsanóczi, J. Németh, S. Bató, Y. U. Nam, G. H. Hu, and S. Zoletnik, "Development of a high current $60 \mathrm{keV}$ neutral lithium beam injector for beam emission spectroscopy measurements on fusion experiments," Review of Scientific Instruments, vol. 89, no. 1, p. 013 503, 2018. DOI: 10.1063/1.5004126.

[9] E. Ragonese, N. Spina, A. Parisi, and G. Palmisano, "An experimental comparison of galvanically isolated DC-DC converters: isolation technology and integration approach," Electronics, vol. 10, p. 1186, 2021. DOI: $10.3390 /$ electronics10101186.

[10] C. Budelmann, "Opto-electronic sensor network powered over fiber for harsh industrial applications," IEEE Transactions on Industrial Electronics, vol. 65, pp. 1170-1177, 2 2018. DOI: 10.1109/TIE. 2017. 2733479.

[11] V. V. Andreev et al., "Gyromagnetic autoresonance plasma bunches in a magnetic mirror," Physics of Plasmas, vol. 24, no. 9, p. 093 518, 2017. DOI: $10.1063 / 1.4986009$.

[12] V. V. Andreev, A. A. Novitsky, and D. V. Chuprov, "The use of streak photography, X-ray radiography, and radiometric and spectrometric measurements to study plasma bunches generated under gyroresonant interactions," Physics of Atomic Nuclei, vol. 82, no. 10, pp. 1404-1413, 2019. DOI: $10.1134 / \mathrm{S} 1063778819100016$.

[13] M. V. Kuzelev et al., "Plasma relativistic microwave electronics," Plasma Physics Reports, vol. 27, pp. 669-691, 8 2001. DOI: 10.1134/1.1390539.

[14] S. E. Ernyleva, V. O. Litvin, O. T. Loza, and I. L. Bogdankevich, "Promising source of high-power broadband microwave pulses with radiation frequency variable up to two octaves," Technical Physics, vol. 59, pp. 1228-1232, 8 2014. DOI: 10.1134/S1063784214080106.

[15] S. E. Ernyleva and O. T. Loza, "Plasma relativistic microwave noise amplifier with inverse configuration [Plazmennyy relyativistskiy SVCHusilitel' shuma s inversnoy geometriyey]," Trudy instituta obschey fiziki im. A.M. Prokhorova, vol. 72, pp. 128-133, 2016, in Russian.

[16] A. B. Buleyko, N. G. Gusein-zade, and O. T. Loza, "Plasma masers: status quo and development prospects," Physics of Wave Phenomena, vol. 26, no. 4, pp. 317-322, 2018. DOI: 10.3103/S1541308X18040118.

[17] A. B. Buleyko, A. V. Ponomarev, O. T. Loza, et al., "Experimental plasma maser as a broadband noise amplifier. II: Short pulse," Physics of Plasmas, vol. 28, p. 023 304, 2021. DOI: 10.1063/5.0031432.

[18] P. A. Blume, The LabVIEW Style Book. NJ: Upper Saddle River, 2007.

[19] P. Ponce-Cruz and F. D. Ramírez-Figueroa, Intelligent control systems with LabVIEW. New York: Springer LDH, 2010, p. 216.

[20] S. Hauck and A. DeHon, Eds., Reconfigurable computing: the theory and practice of FPGA-based computation. New York: Elsevier Inc., 2008. 


\section{For citation:}

V.V.Andreev, D. V. Chuprov, Modeling and design of an re-configurable isolated remote for plasma experiments with hard-real-time synchronization, Discrete and Continuous Models and Applied Computational Science 29 (3) (2021) 205-220. DOI: 10.22363/2658-4670-2021-29-3-205-220.

\section{Information about the authors:}

Viktor V. Andreev - Candidate of Physical and Mathematical Sciences, Assistant professor of Institute of Physical Research and Technology of Peoples' Friendship University of Russia (RUDN University) (e-mail: andreev-vv@rudn.ru, phone: +7(495) 9550827, ORCID: https://orcid.org/0000-0002-2654-6752, ResearcherID: O-2878-2013, Scopus Author ID: 23014039400)

Denis V. Chuprov - Senior Lecturer of Institute of Physical Research and Technology of Peoples' Friendship University of Russia (RUDN University) (e-mail: chuprov-dv@rudn.ru, phone: +7(495) 9550759, ORCID: https://orcid.org/0000-0002-6768-6196, ResearcherID: O-3193-2013, Scopus Author ID: 6508067157) 
УДК 53.087.4:533.9.07

PACS 52.59 Ye, $07.05 \mathrm{Dz}$

DOI: $10.22363 / 2658-4670-2021-29-3-205-220$

\title{
Моделирование и разработка реконфигурируемого пульта управления для плазменных экспериментов с жёсткой синхронизацией в реальном времени
}

\author{
В. В. Андреев, Д. В. Чупров \\ Российский университет дружбъ народов \\ ул. Миклухо-Маклая, д. 6, Москва, 117198, Россия
}

Цель данной статьи - представить дизайн и реализацию реконфигурируемого пульта дистанционного управления для проведения плазменных экспериментов с синхронизацией в режиме жёсткого реального времени при джиттере менее 1 микросекунды. Дополнительным требованием к системе многоканальной синхронизации является использование высокоскоростных оптических преобразователей для обеспечения гальванической развязки между мощными модулями установки и дистанционного управления, чтобы исключить любую возможность нарушения работы системы управления физическим экспериментом.

Моделирование и разработка программной части пульта дистанционного управления мазером проводились в среде разработки приложений LabVIEW с модулями Real Time и FPGA.

Аппаратная часть панели управления реализована на контроллере реального времени, работающем совместно с модулем Xilinx FPGA. Для обеспечения оптической развязки сигналов синхронизации разработаны и изготовлены платы электронно-оптических преобразователей на основе светодиодных лазеров с оптоволоконными выводами.

Программа управления реализована в двухмодульной архитектуре с приложением HOST и приложением FPGA, которые обмениваются данными по сети 1000BASE-T Ethernet.

Ключевые слова: пульт управления, синхронизация, система жёсткого реального времени, настраиваемый ввод-вывод 